\title{
Claims of Representation: Between Representation and Democratic Innovations
}

\author{
Petra Guasti ${ }^{1 * t}$ and Brigitte Geissel ${ }^{2}$ \\ ${ }^{1}$ Charles University, Prague, Czechia, ${ }^{2}$ Goethe University Frankfurt, Frankfurt, Germany
}

\section{OPEN ACCESS}

Edited by:

Pierre-Etienne Vandamme, Université libre de Bruxelles, Belgium

Reviewed by:

Francisco Cantu,

University of Houston, United States

Pieter De Wilde,

Norwegian University of Science and

Technology, Norway

*Correspondence:

Petra Guasti

guasti@soz.uni-frankfurt.de

tORCID:

Petra Guasti

orcid.org/0000-0001-7129-1827

Specialty section:

This article was submitted to Elections and Representation,

a section of the journal

Frontiers in Political Science

Received: 04 August 2020 Accepted: 01 February 2021

Published: 26 March 2021

Citation:

Guasti P and Geissel B (2021)

Claims of Representation:

Between Representation and

Democratic Innovations.

Front. Polit. Sci. 3:591544.

doi: 10.3389/fpos.2021.591544
This article seeks to build a bridge between the empirical scholarship rooted in the traditional theory of political representation and constructivist theory on representation by focusing on the authorization of claims. It seeks to answer how claims can be authorized beyond elections - selecting three democratic innovations and tracing claims through the claim-making process. Different participatory democratic innovations are selected - providing various claims and taking place in different institutional contexts, i.e., (elected) members of the Council of Foreigners Frankfurt; individual citizens in participatory budgeting procedures in Münster; and citizen's associations elected politicians in the referendum campaign in Hamburg. We first analyze the claims raised by the different claim-makers to identify their claimed constituency eligible to authorize claims. In the second step, we focus on the authorization by the claimed constituency and the relevant decision-making authority. The article finds that claim-making in democratic innovations is fractured and incomplete. Nevertheless, this is not the reason to dismiss democratic innovations as possible loci of representation; on the contrary, seen through the prism of claim-making, all representation electoral and nonelectoral - is partial. Focusing on the authorization of claims in democratic innovations provides novel inferences about the potential and limits of democratic innovations for broadening democratic representation

Keywords: representation, representative claim, authorization, democratic innovation, constructivist turn

\section{INTRODUCTION}

The traditional theory of democratic representation centers on the linkage between democracy and representation. It answers the question what makes representation democratic, with two interlinked concepts - authorization and accountability (Pitkin, 1967). At the heart of democratic representation are elections - they are both an authorization mechanism (represented appoint representatives) and providing accountability (represented re-appoint "good" representatives and punish the "bad" ones). Historically, the representation literature focused on the behavior of the representative (delegate vs. trustee model), types of representation (Pitkin, 1967; Mansbridge, 2009), the distinction between representation and participation (Plotke, 1997), and methods for selecting representatives (Manin, 1997).

Recent theories of representation broadened several features (Mansbridge, 2009), the scope of the represented (to include both people and discourses, Dryzek and Simon, 2008), and the role of the representative (citizen representative, Warren and Hilary, 2008). The scholars of the representative turn - mainly constructivists - went further highlighting multiple forms and mechanisms of representation beyond elections rejecting the concept of a principle-agent relationship, and 
introducing reflexivity as a measure of legitimacy (Disch, 2011), reconsidering representation as mediation centered on voice, trust, and memory (Williams, 2000), or as advocacy. They shifted our attention from the formal procedure of election to the expressive and performative dimension of representation (Urbinati, 2000; Urbinati, 2002).

At the core of their efforts is the way in which the fractured relationship between the representatives and the represented in contemporary democracies can be repaired (Mair, 2008; Saward, 2008; Mair, 2009; Dalton et al., 2011; Biezen, 2014; Rosanvallon, 2008). Constructivist democratic theorists reconsidered what is representation and what is the relationship between the representative and the represented. Famously, the British political theorist Michael Saward reconceptualized representation as a claim-making process (Saward, 2006; Saward, 2010). He broadened the scope of representation (actors and procedures) beyond elected representatives and elections, thus bridging representation, participation, and deliberation (Guasti and Geissel, 2019). In the concept of representation as claimmaking, theorists propose to focus on the plurality of claimmakers, claims, and conditions under which claim-making occurs (Saward, 2006; Saward, 2010; Kuyper, 2016).

This development was labeled as the constructivist turn in the political representation literature. This approach offers one possible way to study and perhaps improve the fractured linkage between citizens and representatives (e.g., Disch et al., 2019). However, broadening the scope of representation beyond electoral authorization opens up a conceptual and empirical challenge. When representation is claim-making, and elections are one but not the only authorization mechanism, it is no longer evident who speaks for whom and whether and how the claims of self-selected representatives can be authorized (Warren, 2001; Urbinati and Warren, 2008; Montanaro, 2017).

However, a conceptual and analytical framework allowing to grasp the cacophony of claims and alternative forms of their authorization was missing until recently (cf. Guasti and Geissel, 2019; Guasti and Rezende de Almeida, 2019; Joschko and Glaser, 2019; de Wilde, 2020). The lack of such a framework was probably the reason why empirical research in this field is rare and limited, focusing mainly on the behavior of claim-makers (de Wilde, 2013; de Wilde, 2020) or a few studies trying to develop new mechanisms of authorization (Kuyper, 2016; Joschko and Glaser, 2019). The empirical scholarship remained primarily rooted in the traditional representative theory - focusing on elections, characteristics and the behavior of the representatives (Przeworski et al., 1999). A typology developed by Guasti and Geissel (2019) proposed a way to connect constructivist democratic theory and empirical research - a novel way to study representation as claim-making (Guasti and Geissel, 2019). What remained absent was a systematic empirical analysis of authorization.

This article seeks to build a bridge between the empirical scholarship rooted in the traditional theory of political representation and constructivist theory on representation by focusing on the authorization of claims. We select different participatory democratic innovations providing various claims and taking place in different institutional contexts, i.e., (elected) members of the Council of Foreigners Frankfurt; individual citizens in participatory budgeting procedures in Münster; and citizen's associations elected politicians in the referendum campaign in Hamburg. ${ }^{1}$ We first analyze the claims raised by the different claim-makers to identify their claimed constituency eligible to authorize claims. In the second step, we focus on the authorization by the claimed constituency and the relevant decision-making authority.

\section{CONCEPTUAL FRAMEWORK: CLAIMS ON REPRESENTATION AND AUTHORIZATION}

The constructivist turn freed representation from the sole focus on electoral politics (Manin, 1997) by emphasizing claim-making (Saward, 2006; Saward, 2010). While traditional representation is confined to the halls of parliaments, constructivist representation as claim-making is everywhere. Instead of parties competing in elections, multiple competing claims on behalf of affected groups or abstract normative schemes emerge and compete for the attention and recognition in the public sphere (Andeweg, 2003; Saward, 2006; Rosanvallon, 2008; Van Biezen and Saward, 2008; Kuyper, 2016; Montanaro, 2017; Disch et al., 2019). Elected representatives are no longer the sole actors in the representation process, and electoral politics are not the only loci of representation. This is both an opportunity and a challenge for scholars of representation. On the one hand, nonelected actors claim to represent a wide range of constituencies (Montanaro, 2017), which often fall below the radar of electoral politics (de Wilde, 2013). On the other hand, if representation is everywhere, and everybody can make claims of representation, it is difficult to grasp conceptually and empirically study something like representation (Guasti and Geissel, 2019; cf.; Näsström, 2006: 326; Phillips, 1995; Mansbridge, 1999)

Along with the question of how to cope with the variety of new claim-makers comes the question of authorization. The public sphere is full of claim-makers-some elected, others non-elected. How can these claims be authorized? And by whom? Taking the challenge to the authorization monopoly of elections seriously forces us to think beyond the existing electoral paradigm. ${ }^{2}$ This article seeks to link the constructivist focus on claims with the traditional focus on the authorization. The conceptual and analytical framework developed by Guasti and Geissel (2019) provides an avenue for systematic empirical research of who claims what and whether acceptance constitutes a possible form of authorization (on acceptance in the context of symbolic representation see Pitkin, 1967).

\section{Claims on Representation: A New Typology}

Traditional scholars of representation are currently seeking ways to improve representation. However, in their effort, they remain constrained by relying on traditional institutions (parties, elections) and actors (politicians, voters, the opposition)

\footnotetext{
${ }^{1}$ We select democratic innovations on local and state levels in Germany - the council of foreigners in Frankfurt (2005-2017), participative budgeting in Münster (2011-2016), and school reform referendum initiated by citizens in the city-state Hamburg (2008-2010). The cases were selected to include various actors and concepts, but including a formal authorization mechanism.

${ }^{2}$ Especially disputed are the categories of audience and referent (Disch, 2015).
} 
(Pitkin, 1967). For the scholars of the constructivist school, these institutions constitute some, but not the sole loci of representation. Instead, they lead an ongoing debate on representation as claim - making.

The first question in this context is: what constitutes a claim (Saward, 2006, Saward, 2010; de Wilde, 2013; Disch, 2015; Guasti and Rezende de Almeida, 2019). Most authors refer to Saward's general definition that a "representative claim" is "a claim to represent or to know what represents the interests of someone or something." (Saward, 2006). Saward's definition is theoretically sound but empirically ambivalent. Its ambivalence undermines its empirical applicability. While the traditional scholars of political representation do not see the forest for the trees, constructivist scholars of political representation walk around the forest looking for the trees. Traditional scholars do not see beyond the paradigm of electoral politics. Constructivist scholars recognize the chaos of claims but struggle with operationalization and systematic analysis. We propose to focus on the trees - claims, their acceptance, and authorization.

In an iterative process, Guasti and Geissel (2019) we developed a comprehensive typology of representative claims. Based on analyses of several real-life cases, we made five relevant points on (the analysis of) claim-making. First, claims are often incomplete, and not all elements outlined by Saward and others are necessarily included (see below; de Wilde, 2013; de Wilde, 2020). Second, claims of representation with explicit reference to a claimed constituency are rare (Guasti and Geissel, 2019). When it comes to the authorization of claims, the constructed linkage between the representative and the represented is key. Some claim-makers explicitly construct a linkage between them and the represented (e.g., "as a mother I represent mothers"), others simply imply a linkage (e.g., "mothers like me") or do not construct a linkage (e.g., "more money is needed"). The presence (or absence) of such a linkage makes a vast difference in the authorization of claims. In other words, is a constituency named (e.g., "mothers"), which could potentially authorize the claim or not (ibid. 2019; cf. Sartori, 1987; Kitschelt, 2000). Fourth, outside the electoral arena, non-elected claim-makers often challenge elected representatives. Authorization provided to the elected representatives by election does not go hand in hand with the actual representation of respective constituencies-thus claims of misrepresentation emerge (Guasti and Rezende de Almeida, 2019). Fifth, the "subject" of representation (what is represented) is often not a "human being," but a "normative scheme," e.g., justice, freedom (e.g., Dryzek and Simon, 2008; Joschko and Glaser, 2019). ${ }^{3}$

\footnotetext{
${ }^{3}$ We distinguish between two types of the claimed "constituency" - human beings and normative schemes (cf. Pitkin, 1967; Pitkin, 2004; Runciman, 2007; Mansbridge, 2011). We recognize that claims to normative schemes appeal to an actual human constituency - i.e., to those sharing the values of justice and freedom. However, the reception of this claim will be different. To accept or reject a claim, e.g., to "justice," the audience member should first assess whether justice is grounds for accepting a claim (cf. Montanaro, 2017 on affected interests; Ankersmit, 2002, Näsström, 2006 on aesthetic aspects of representation).
}

\section{Elements of Claims}

In order to empirically capture claims, we need to define the key elements of claims. Guasti and Geissel (2019) focus on what is claimed to be represented - the (claimed) constituency, who is expected to act on behalf of the claimed constituency - the claimed representative, and the linkage between the (claimed) representative and the (claimed) constituency (Table 1). ${ }^{4}$

The three categories can be applied to both electoral and nonelectoral context. For illustration, we use an example familiar to scholars of traditional electoral representation: in an electoral campaign rally, the candidate of a populist radical right party claims that the establishment parties no longer represent "true national values," and voters should instead support its candidate, a former soldier. Here, the candidate first vacates the existing linkage between the elected representatives and the constituency and claims to represent "true national values" IF elected. The constituency is those voters for whom "true national interest" is an electorally salient issue. The linkage emerges thru acceptance of the claim and is confirmed by authorization in elections (cf. Guasti and Rezende de Almeida, 2019).

In the process of claim-making, claim-makers construct constituencies (e.g., "I represent citizens with true national values"), rendering them politically present ("true national values" as a campaign theme) (cf. Disch, 2011). Claim-makers claim to make non-represented constituencies visible and audible - people previously 'left behind' (Hirst, 2013; Williams, 2000; Disch, 2011; Montanaro, 2012). We have used the example of electoral politics to make our abstract argument more comprehensible for non-constructivist scholars. However, we could also speak of Greta Thunberg, calling for climate justice on behalf of future generations and mobilizing youth within the Fridays for Future (cf. on Thunberg and Fridays for Future, Zulianello and Ceccobelli, 2020). In this example, Greta Thunberg (claim-maker) constructs her constituency (youth who mobilizes around climate justice), creating the Fridays for Future movement (nonelectoral linkage).

The object of representation - claimed constituency - is constructed in the process of claim-making. Claim making puts different "ideas" of 'the represented' into play and opens them up for contestation. (to stay with our example, climate emergency has both vocal supporters and opponents claiming to speak on behalf of future generations). A claim depicts the object of representation in a particular way, as having a particular set of interests (cf. Bourdieu, 1991; Saward, 2006; Montanaro, 2012). Fridays for Future defines future generations' interests, which they claim conflict with the

${ }^{4}$ The "representative claim" literature uses the term "object of representation to describe the represented." In contrast, the traditional representation theory speaks of the "constituency." Here, we use both terms as synonyms to depict constituency beyond the confines of the individualist approach (Pitkin, 1967) - individuals, groups, normative schemes (cf. Runciman, 2007, Mansbridge, 1999, Mansbridge, 2003; Mansbridge, 2011; Mansbridge, 2015). 
TABLE 1 | Elements of claims on representation.

\begin{tabular}{|c|c|c|}
\hline Element & Definition & Example \\
\hline Claim maker & Who speaks & I represent all citizens \\
\hline Claimed representative & Who is expected to act on behalf of the claimed constituency & Social democratic parties (should) represent workers \\
\hline Claimed constituency & On whose behalf subject claims to speak & KAV represents the muslim population of Frankfurt \\
\hline Claimed linkage & The claimed connection between the claim maker and the claimed constituency & I stand for your interests \\
\hline
\end{tabular}

Source: Guasti and Geissel (2019).

current politics. Alternatively, another example from our research, the Council of Foreigners (KAV), our Frankfurt case, demanded the introduction of special hours for women in public pools in Frankfurt. ${ }^{5}$ Thus, KAV insinuated that Muslim female foreigners have a particular interest - to have access to swimming without men's presence.

Guasti and Geissel (2019) distinguish between two types of claimed constituency - human beings and normative schemes. This distinction allows the identification of various linkages claimmaker constructs between the claimed representative and the claimed object. Both of our examples used normative schemes and showed how normative schemes are not only abstract discourses (Dryzek and Simon, 2008) but appeal to real-life people.

In the next phase (authorization of claim), this distinction provides grounds for distinguishing various authorization mechanisms. A claim to the human constituency constructs direct linkage and thus enables the claimed constituency to accept or reject the claim. Claims to normative schemes establish indirect linkage between the representative and the represented and presumed authorization by those who perceive themselves as affected as well as by decision-making authorities, who accept or reject the claim-maker as representative of the respective normative scheme (Montanaro, 2017; Guasti and Geissel, 2019).

Some claim-makers start their claim with an accusation of misrepresentation, questioning the linkage (and the legitimacy) of other claim-makers (Disch, 2009: 52). For example, in their work on claims of misrepresentation, Guasti and Rezende de Almeida (2019) show how the alternative for Germany denies the existence of linkages between social democratic parties and workers in order to present itself as the new representative of German workers. Focusing on the presence, denial, and absence of the claimed linkage between the representative and the represented allows us to distinguish various types of claims and their possible authorization modes.

\section{The Typology}

Based on a comprehensive iterative process, Guasti and Geissel (2019) identified four different types of claims based on the three elements outlined above - constituency, representative, and linkage. Some are "complete" and include all elements: The claims of representation presumably speak for a constituency and indicate linkages between the claimed representatives and the claimed constituencies. Other claims do not include all elements, e.g., claims of interest claim to speak for a community, but do not claim a linkage, and so on (see Table 2).

\section{Conceptual Framework for Empirical Analysis of the Authorization of Claims}

The acceptance of claims is central to the constructivist literature - it is a form of authorization - legitimizing the claim-maker to represent the constituency (Saward, 2006; Disch, 2015; Montanaro, 2017). Classical literature uses the term authorization, which is reserved for elections and eligible actors, i.e., members of the government, members of parliament, and the president (Pitkin, 1967). Since the constructivist scholars proposed to go beyond elections as sole authorization mechanisms, the literature on representative claims discusses alternative forms of authorization (Montanaro, 2012; Severs, 2012; Saward, 2009; Disch, 2015; Kuyper, 2016; Montanaro, 2017; Dryzek and Simon, 2008).

A variety of different terms evolved, for example, acknowledgment, reception, perception, absorption, engagement, legitimacy, accountability, legitimation, resonance, responsiveness, judgment, congruence, affectedness, resemblance, expertise, assessment, credibility, recognition, evaluation, inclusivity, or consequentiality (Dryzek and Simon, 2008; Saward, 2010; Montanaro, 2012; Severs, 2012; Disch, 2015; Kuyper, 2016; Montanaro, 2017). Most of these terms are used abstractly and rarely operationalized, making the empirical application difficult (see Joschko and Glaser, 2019 as an example of successful operationalization and data use). In particular, the representative turn literature places a significant emphasis on authenticity (e.g., affected interests in Montanaro, 2017, substantive representation in Severs, 2012). ${ }^{6}$ We perceive this approach as reductive and do not recognize authenticity as a functional equivalent of authorization. Authenticity as an authorization mechanism shifts the focus away from the linkage between the representatives and the represented, reducing it to a (descriptive) fit (e.g., black women represent black women) - the underlining assumption being, the better the fit, the better the representation (cf. Mansbridge, 2011; Mansbridge 2013; Heinisch and Werner, 2019; Joschko and Glaser, 2019). Guasti and Geissel (2019) proposed to seek empirical ways to assess the authorization of claims, rather than developing alternative theoretical concepts (cf. Disch, 2009).
${ }^{5}$ The constituency question has become a critical problem in the representation theory and remains largely ambivalent (Montanaro, 2017).
${ }^{6}$ For many authors, there is also a close-link between self-selected representatives and authenticity (Saward, 2008; Montanaro, 2012). 
TABLE 2 | Types of claims.

Types of claims

CLAIM OF REPRESENTATION claim maker speaks for/on behalf of the claimed constituency and indicates a linkage between him-/herself and claimed constituency CLAIM OF MISREPRESENTATION claim maker accuses another representative not to represent the claimed constituency and denies a linkage between other representative and claimed constituency

CLAIM OF INTERESTS/VALUES claim maker speaks of interests and values, referring explicitly/implicitly to a claimed constituency without indicating any linkage to claimed constituency

PROCLAMATION claim maker states a proposal without referring to a claimed constituency and without indicating any linkage to claimed constituency

\begin{tabular}{|c|c|c|}
\hline Constituency & Linkage & Example \\
\hline referenced & referenced & $\begin{array}{l}\text { We [KAV] represent the muslim population of } \\
\text { Frankfurt }\end{array}$ \\
\hline referenced & Denied & $\begin{array}{l}\text { The government [of Hamburg] does not represent } \\
\text { the interests of pupils }\end{array}$ \\
\hline referenced & Absent & $\begin{array}{l}\text { The reform is needed to improve children's } \\
\text { education }\end{array}$ \\
\hline Absent & Absent & More park benches are needed \\
\hline
\end{tabular}

Source: Guasti and Geissel (2019); examples adapted from the current case studies.

Three approaches combined conceptual advancement and empirical assessment of authorization (Kuyper, 2016; Heinisch and Werner, 2019; Joschko and Glaser, 2019). Kuyper (2016) identified key criteria for assessing nonelectoral representatives and deliberative democratic legitimacy (inclusivity, authenticity, and consequentiality). While Kuyper;s approach significantly contributes to understanding nonelectoral representation, it assesses the process as a whole. It does not allow us to zoom in on claims as key elements of representation. The remaining two approaches (Heinisch and Werner, 2019; Joschko and Glaser, 2019) used claims but focused on electoral representation. Heinisch and Werner (2019) measured claims by populist parties in their programs, whether voters accept these claims (by voting), and the extent to which elected representatives descriptively represent the claimed groups. While enriching the study of representation with some features of the constructivist approach, it remains firmly in the (narrow) space of electoral representation - providing important information about claims by populist parties and their reception by voters. However, the election remains the ultimate authorization mechanism. Joschko and Glaser (2019) sought to measure reception and validation of claims by elected representatives beyond the election. Using sophisticated methods to identify constituencies using multiple correspondence analysis and to assess validation, they used natural language processing and regression on social media data. While we appreciate this approach, such type of data is not available for most claims made outside the parliamentary arena and attention of social media. It is thus not available for most scholars of nonelectoral representation.

Who can authorize claims by non-elected representatives? For Dovi (2017), the claimed constituencies are the ultimate authority in assessing the claims. However, according to Saward (Saward, 2010: 186) and Disch (Disch, 2015: 494), a distinction ought to be made between "claimed constituency" (the constituency constructed by the claim) and "effective audience" defined as actors with resources and power, which can make a useful contribution, for example, authorities, mass media, or "the public" (cf. Saward, 2010; Disch, 2015). In assessing the claims by not-elected representatives, we distinguish between "claimed constituency" and "decision-making authority" (Guasti and Geissel, 2019, cf. Joschko and Glaser, 2019). Decision-making authority can be, for instance, a parliament, a mayor, or in case of a referendum (such as the referendum in Hamburg), the citizenry. These decision-making authorities decide which claim to accept.

A framework of analysis, considering the different types of claims and "accepting actors" (claimed constituency, decisionmaking authority), is described in Table $\mathbf{3}$ and discussed below.

The empirical application of this framework is demanding. How can we find out whether the claimed constituency and the relevant authority accepts or rejects a claim? Considering claims of representation by non-elected claim makers, Guasti and Geissel (2019) propose identifying the claimed constituency. Where claimed constituencies exist, both the authorization by "claimed constituency," and "decision-making authority" can be examined. Considering normative schemes, in our cases, authorization can only be assessed by the authorities (for an alternative approach to authorization of claims by self-selected representatives, see Montanaro, 2017; Kroeber, 2018; Guasti and Rezende de Almeida, 2019).

For example, an animal advocacy group claims to represent "justice for farm animals." This claim cannot be accepted directly. At present, we cannot grasp the notion of justice espoused by farm animals (if it exists). Furthermore, the authorization of this claim can not be measured via election (animals can not elect their representatives). The decision-making authority (e.g., the Ministry of Agriculture) can accept the claim and invite the animal advocacy group to submit a proposal on improving the well-being of farm animals.

\section{CASE STUDY DESCRIPTION AND METHODOLOGY}

To assess the authorization of claims in the context of democratic innovations, we proceed to apply our typology to three cases. ${ }^{7} \mathrm{We}$

\footnotetext{
${ }^{7}$ Three criteria were used to identify these case studies: 1) theme - issues related to various types of representation (descriptive, substantive, and critique of representation), with and without electoral authorization (elected, self-selected claim-makers); 2) scope - we include both state and municipal level debates; 3 ) comparability (our project is a part of a broader international framework, case selection was adjusted to allow for comparison of cases across various countries for example, after completing the analysis of participative budgeting in Münster, we will be able to compare the German case to France, Brazil and India; in this article, our analysis only includes the German cases).
} 
TABLE 3 | Authorization of different claims.

\begin{tabular}{|c|c|c|}
\hline Type of claim & $\begin{array}{l}\text { A. Authorization by } \\
\text { the claimed constituency }\end{array}$ & $\begin{array}{l}\text { B. Authorization by } \\
\text { the relevant decision-making } \\
\text { authority }\end{array}$ \\
\hline CLAIM OF REPRESENTATION & Yes (direct) & Yes \\
\hline CLAIM OF MISREPRESENTATION & Yes (direct) & Yes \\
\hline CLAIM OF INTERESTSNALUES & Yes (indirect) & Yes \\
\hline PROCLAMATION & No (not applicable) & Yes \\
\hline
\end{tabular}

Source: Guasti and Geissel (2019).

compare three recent democratic innovations on local and state level in Germany - participative budgeting in Münster (municipal level, 2011-2016, representation without elections), the council of foreigners (KAV) in Frankfurt (municipal level, 2006-2017, electoral representation beyond citizenship), and the school reform referendum initiated by citizens in Hamburg (state level, 2008-2010, direct democracy). ${ }^{8}$

We collect primary data (case-specific - transcripts of debates, online debates, printed media, and social media). Our analysis combines content and discourse analysis. We proceed in three steps. First, we identified all available documents related to the given topic (in the case of Münster and Frankfurt proposals by citizens (Münster) and KAV (Frankfurt) online; in the case of Hamburg, we selected two local print media and analyzed articles referring to school referenda for the period 2006-2017, as well as press releases of the various actors, etc.).

Second, we coded the three elements of the claim described above (see Table 1): the claimed representative, the claimed constituency (assigning the category of a human being or normative scheme), and the claimed linkage, respectively ${ }^{9}$.

In the next step, we focus on the authorization of claims. We open up our analysis with a democratic innovation that is the closest to traditional representative politics. Non-citizen residents of Frankfurt elect KAV, and KAV is tasked with representing this constituency of foreigners as a whole. Its outputs are claims (recommendations and requests) to the Frankfurt municipal government (decision-making authority). Tracing KAV claims through the process allows us to assess the authorization of claims both by the constituency and decision-making authority. Our second case, the participative budgeting in Münster, is a classic case of democratic innovation, which allows us to trace claims through all three stages of claim-making. Unlike in the case of KAV in Frankfurt, there is no authorization by elections. Instead, the authorization of claims by the constituency takes

${ }^{8}$ While not universally accepted, in the German context, direct democracy is recognized as a form of democratic innovation (Geißel and Joas, 2013).

${ }^{9} \mathrm{We}$ performed an intercoder reliability test to ensure the validity of our coding. Two members of the research team codded all claims separately, using pre-agreed categories. Intercoder reliability test was performed regularly, including all coded claims (Cohen's kappa, $\mathrm{K}$, where complete agreement $K=1$ ). In all intercoder reliability tests, the value of Cohen's kappa was above 0.85 . Those items where coders did not reach an agreement were subsequently discussed and recoded. place online. Subsequently, the decision-making authority assesses the claims. Finally, in the case of the Hamburg school reform referendum, voters are the ultimate decisionmaking authority.

\section{ANALYSIS}

\section{Council for Foreigners in Frankfurt}

The Council for Foreigners (Kommunale Ausländervertretung, $\mathrm{KAV}$ ) is a body for foreigners' municipal representation in Frankfurt (Germany). KAV is elected by the city's residents without a German passport to represent their interests. The electoral term is five years. KAV was first founded in 1991, and KAVs are established in all Hesse municipalities with at least 1,000 registered foreign residents.

$\mathrm{KAV}$ can make requests and questions to the municipality. We have analyzed all requests and claims between 2006 and 2017 identifying 284 claims. The most often used type of claim is claims of interests/values (52\%); the least used type are claims of misrepresentation (11\%).

\section{Claimed Constituency}

Regarding the claimed constituency, we found that the majority of claims (58\%) are related to human beings. Human beings as the claimed constituency are most often foreigners/migrants, nonGerman speakers, Muslims, asylum seekers, refugees, migrant children/youth, migrant associations, non-Christian patients in hospitals.

Normative schemes (32\%) are most often inclusiveness, diversity, integration, anti-discrimination, public safety, sustainability, multiculturalism, tolerance, equal treatment, public health and safety, and religious freedom (always vis-àvis Islam). Conceptually, we see that the distinction of constituency between human beings and normative schemes is essential. The use of the category normative schemes enables us to identify the constituency behind these normative schemes, such as here, in our example, where "religious freedom" is a frame used to push for more accommodation for Frankfurt's Muslim population.

\section{Authorization}

$\mathrm{KAV}$ is an elected body, and its constituency is the foreign population of the city. In a city with 150 nationalities, many of whom do not have voting rights, KAV is the only body of political representation. The authorization mechanism is 
elections. Over the 2 decades, the turnout in the KAV elections decreased significantly (from $7.9 \%$ in 1997 to $6.2 \%$ in 2015). The turnout in KAV elections demonstrates that KAV failed to attract its constituency.

As the KAV turnout is extremely low and further decreasing, critical voices for the abolition of KAV are strengthening. These voices cite the lack of acceptance/authorization among the foreign population and the lack of willingness of KAV to fulfill its mandate 'representing the foreign population as a whole.'

In order to assess the level of authorization of KAV claims by the relevant authority - the Frankfurt municipal government - we traced each claim individually through the process. We found that a significant number of the KAV proposals were rejected (31\%), a small number accepted (10\%), and the majority were processed by the municipality (59\%). Our analysis shows that the low acceptance and high rejection rate is not an attempt of the municipality to go against Frankfurt's foreign residents' interests. Instead, KAV's demands are often in direct opposition to the city's liberal policies.

The majority of the accepted claims $(N=16)$ were congruent with the Frankfurt City Government's desire to create an open and inclusive society. The accepted claims included introducing intercultural competence and multilingual staff in the office for seniors to improve access for non-German speaking seniors. Upon a KAV request, a stricter approach was adopted in order to impede hate crime. Some general changes included road adjustment, the location of public toilets in the city, and the improvement of the train station's ambiance.

The majority of the rejected KAV claims $(N=50)$ tend to represent specific interests of male Muslim-conservatives seeking to insulate their particular constituency from integration. This KAV demands clash with the existing policies of the City Government. These claims are also incongruent with the KAV's official mandate and do not intend to represent Frankfurt foreigners' interests as a whole. Instead, they seek to represent the interests of the (conservative) Muslim population of the city, regardless of citizenship. For example, the KAV attempts to separate swimming pool hours for Muslim women in the city's public pools.

Some rejected claims also seek to redefine KAV as representative of Muslim residents (regardless of their citizenship status - i.e., both dual citizens and foreigners). Given the frequency of these requests, over time, the City Government views KAV with growing suspicion (and contempt). The perception of KAV as able to represent the interests of the Frankfurt non-citizens population continues to deteriorate.

To summarize, the significant finding of this case study is that the KAV constituency designated by law (the foreign-population of Frankfurt) is not identical to the claimed constituency (Muslim population of Frankfurt). The failure to represent the foreign population as a whole has significant repercussions regarding the authorization of KAV claims - the KAV elections experience meager turnout, and call for its abolition are increasing. The decision-making authority rejects most KAV claims because they represent partial interest contrary to the city's values. KAV fails to represent its constituency (foreigners living in Frankfurt) - and is neither accepted by this constituency nor authorized by the authority.

\section{Participative Budgeting in Münster}

In Münster, the process of participatory budgeting is divided into five phases: 1) proposals are made public by the city municipality and discussed by participants - anyone interested can hand in proposals via telephone, in written form, or online, upon registering online. In every round, one specific thematic priority is announced; however, proposals to any other issue are also welcome; 2) the residents of Münster are invited to evaluate the submitted proposals - all proposals are published online. Residents of Münster (upon completing the online registration, the minimum age for participating in the evaluative process is 14 years) can evaluate each proposal (options: approval, rejection, neutrality, or abstention); 3) the municipality examines and documents the most popular proposals - proposals which can be realized immediately are implemented as quickly as possible. If it is not feasible, the city council explains the refusal in a written statement online (accountability); 4) residents can again comment on this announcement. Other, more far-reaching proposals are discussed in the next step, and 5) politicians debate and adopt the budget; and the municipality gives account to the citizens.

A dedicated website, run by the municipality, is used for communication from the municipality to the participants/ residents and discussion among participants in the process. We report the analysis of 20 randomly selected proposals from the 2016 debate (third of the four rounds organized to today). We have found that in 19 of the 20 proposals, the claim-maker is explicit and different from the subject. The claim-maker is the citizens, while the subject of the claim, which the maker expects to act, is the municipality. Only in one case did a participant use an impersonal claim - "xx should be done.'

\section{Claimed Constituency}

The majority of claims (16 of the 20) referred to normative schemes - mainly "common good." Only four claims referred to particular interests (including cyclists, municipality, city budget, and music lovers). In 11 cases, the maker claimed the absence of competing interests. In five cases, the maker identified a particular group affected by the proposal and have competing interests - church/religious citizens, car drivers, French literature fans, citizens renting community gardens and parents of kindergarten children.

\section{Authorization}

In Münster, similarly to Frankfurt, we traced the proposals through the whole process to assess the authorization of claims. In tracing the claims, we proceeded in three steps; first, we assessed whether it was regarded as relevant by the participants (first stage). Second, we analyzed if the claim was accepted/rejected by the city council (second stage). Third, we identified whether the proposed claim was taken up and implemented by the local administration (third stage).

The perception of relevance - eight of the twenty claims were perceived as relevant by the participants (voted into the "best of" 
list online). Regarding authorization by the city council, eight proposals/claims were accepted, and the city council rejected four. Three of the eight accepted proposals/claims were also implemented. We found only partial, but not full, overlap between authorization by the participants and by the city council. Overall, $40 \%$ of the citizens' proposals were taken up, and $15 \%$ were taken up and implemented. Only $20 \%$ of the proposals were rejected.

To summarize, Münster PB highlights that the design of a democratic innovation is decisive for the process of claimmaking. Further analysis of the relationship between institutional design and claim-making is beyond the scope of this article. Münster PB clearly illustrates the relationship between the authorization of claims by the intended constituency and the decision-making authority. The Münster municipality reviewed claims regarded as relevant by the participants of the online participative budgeting and implemented some. In the end, $15 \%$ of claims made by the participants were accepted by both the participants and the municipality and implemented. In Münster, the decisionmaking authority did not consider claim makers as representatives. Instead, effectiveness and feasibility emerge as authorization framework.

\section{School Reform Referendum in Hamburg}

The institution of a referendum is a part of a set of direct democratic devices (Volksgesetzgebung, citizen lawmaking) introduced in Hamburg in $1996^{10}$. Between 1996 and 2018, four citizens" initiatives were directly related to our case, the Hamburg school reform. Three finished in the citizen legal initiative stage by not reaching the quorum; one organized by the initiative 'We want to learn' (WWL, Wir Wollen Lernen) succeeded. On July 27, 2010, overruled the school reform adopted by the Hamburg parliament. In this case study, we focus on this last procedure.

The focus of this case study was the debate and subsequent referendum on school reform in Hamburg. The core of the debate occurred between 2008 and 2010 on the local and state levels (Hamburg is a city-state). Both the debate and the outcome of the referendum also echoed on the federal level. ${ }^{11}$

The Hamburg debate was extremely polarized along two dividing lines: politics and policy. The political dividing line was between the governing coalition (CDU-GAL) and the

\footnotetext{
${ }^{10}$ It is historically rooted in the 1921 Hamburg Constitution, which included two types of citizen participatory devices: citizen legal initiative (Volksbegehren) authorizing citizens to bring legislation to the parliament by collecting signatures referendum (Volksentscheid) challenging decisions and legal norms adopted by the parliament. This tradition was interrupted by the national socialist regime, and not restored in the 1952 Hamburg Constitution was reintroduced in 1996 (Articles 48 and 50 of the Hamburg Constitution), and reformed in 2004 (in effect since 2005, introduced new thresholds) and 2007 (removing thresholds added in 2004).

${ }^{11}$ Many federal states saw the Hamburg school reform as a test case for a potential broader overhaul of the German educational system. The coalition between the Christian Democrats (CDU) and the Greens (GAL) was the first of its kind in Hamburg and was perceived as a potential model for a similar coalition on a federal level.
}

opposition (parliamentary opposition SPD and Linke, and extra-parliamentary opposition FDP and NPD). On policy, the dividing line was between the proponents (GAL, CDU, citizen initiatives such as Prima School, Pro-Reform, trade union GWE, Student and parent groups) and opponents (SPD, to a lesser degree Linke for whom the reform did not go far enough, FDP and even NPD for whom it went too far and especially the citizen's initiative WWL).

In spring 2010, when it became clear there will be a referendum and its outcome is less than secure, all parliamentary political parties (CDU, GAL, SPD, and Linke) agreed to support and campaign for the reform. After the failed referenda, the resignation of the Mayor (CDU), fall of the CDU-GAL coalition, the new CDU leadership renounced the reform and, in a U-turn (attempt to win back its base), nominated the WWL leader onto the fifth place on the ballot in the 2011 (preliminary) elections.

\section{Claimed Constituency}

In Hamburg, we analyzed 70 claims throughout 2008-2010 Both the number and the types of claims fluctuate over time. Overall, the most often used type of claim is a claim of misrepresentation (43\%); the least used category is the claim of representation (19\%).

Regarding the claimed constituency, we found that most claims (55\%) are related to human beings - children, pupils, students, parents, including underprivileged children (poor, children with migration background). The claims to normative schemes $(45 \%)$ were mostly related to social inclusion, social integration, and justice. The opponents mostly related their claims to the human constituency (the children), while the proponents of normative schemes and human beings. Overall, $79 \%$ of claims were by proponents, $16 \%$ by opponents, and $5 \%$ were neutral.

\section{Authorization}

Given the character of the Hamburg case, the authorization took the form of voting in the referendum. The citizens could vote on both proposals: the anti-reform proposal by the citizen's initiative "We want to learn" and the Hamburg government (see Figure 1).

The outcome of the referenda differed significantly from the claims. In the end, $22 \%$ of Hamburg voters supported the WWL proposal against the reform, and only $17 \%$ supported the reform. The turnout was approximately $40 \%$ and significantly skewed by class - the turnout was extremely low in Hamburg's workingclass neighborhood and very high in upper and middle-class boroughs.

To summarize, the Hamburg school reform highlights the gap between the affected audience and the legal constituency. The school reform was an attempt by a government to improve access to education for children with a migrant and working-class

\footnotetext{
${ }^{12}$ The claims were identified in media articles and public speeches. We selected right-leaning and left-leaning newspapers and collected 53 and 113 articles, respectively.
} 


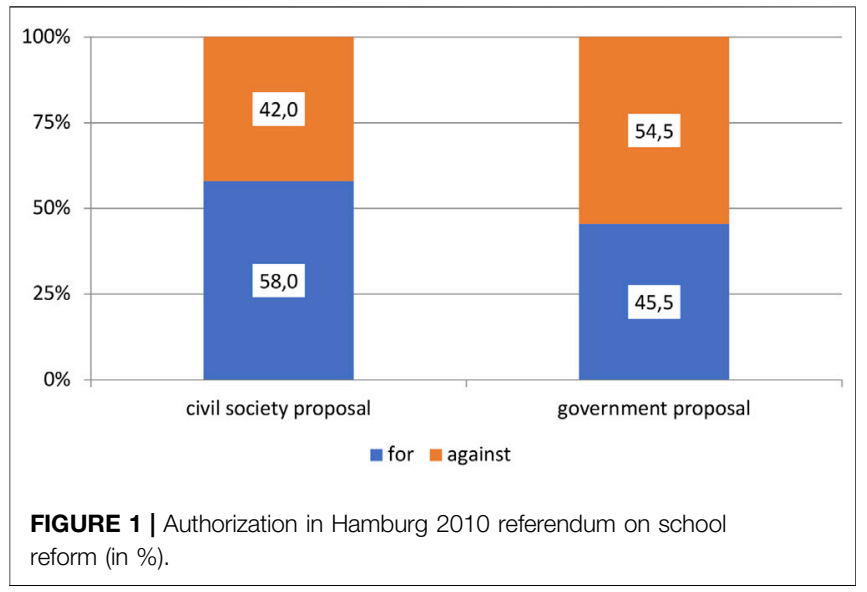

background. The Hamburg middle and upper classes were able to utilize direct democracy to maintain the status quo. In decision-making authority. In this case, the majority of those whose interests were affected were either disfranchised (nonGerman population, children, students), or their capacity to participate was limited (working class, unemployed). ${ }^{13}$ Elected representatives aiming at protecting the interests of minority and vulnerable people were challenged by those better equipped to pursue their interests. The voters - the decision-making authority - authorized the claim by the opponents of the government proposal. ${ }^{14}$

\section{Summary: Claims in Democratic Innovations}

In this part, we will compare the claims on representation in the three democratic innovations. We will focus on the three stages of claim-making - identifying the constituency, assessing authorization, and outlining acceptance (Table 4 provides a comparative overview).

\section{Claimed Constituency}

Our distinction between human beings and normative schemes has proven meaningful in our analysis, as it allowed us a better grasp of the authorization of claims. In Frankfurt and Hamburg, most claims were related to human-beings, but normative schemes were also utilized. In Münster, all claims were related to normative schemes. referenda, as in the case of elections, voters are the ultimate

The case of Frankfurt highlights the clash between the intended constituency (i.e., the foreign population of Frankfurt 'as a whole') and self-perception of KAV, and especially by the dominant KAV group (conservative Turkish males). This makes KAV extremely ineffective and unpopular with the decisionmaking authority (Municipal Council), municipal administration) and the voters.

In Hamburg, the opponents mostly related their claims to children (human constituency). Among the proponents, the specific group of claim-makers referred to inclusion and legitimacy (normative schemes), highlighting the gap between affected interests and those able to participate in authorization (due to age and citizenship restriction of the Hamburg electoral law).

\section{Authorization and Acceptance of Claims}

Studying three democratic innovations, we have found out that authorization results from a complex interplay between the constituency and decision-making authority. Through a twostep analysis (identification of constituency and authorization), we have found out that only between 10\% (Frankfurt) and $40 \%$ (Münster) claims are accepted. On the constituency, an important insight from our case studies is the need to distinguish between claimed constituency, intended constituency, and actually affected audience. In Frankfurt, the lack of overlap between claimed and intended constituency led to limited authorization. In Hamburg, the claimed constituency overlapped with the affected audience. However, only a small portion of those whose interests were affected were enfranchised and capable of participation in the authorization process (referenda). In Münster, the design of the participative budgeting pre-defined the affected interests. When it comes to the authorization via the authorities, effectiveness, and feasibility were key criteria against which the claims were measured in Münster. Thus, the process of participative budgeting was limited in the scope of interests, which could be claimed.

Our study shows that the overlap between claimed constituency and intended constituency is key for the authorization of claims by the decision-making authority. In Frankfurt and in Münster, only claims where claimed constituency overlapped with the intended constituency were accepted. In Hamburg, voting-age citizens were the decisionmaking authority; this significantly undermined the proponents of the reform and led to its failure. To fully grasp the authorization of claims beyond elections, we need to analyze both the claim-making and the authorization of claims.

\section{CONCLUSION}

citizenship. The educational expert commented on the referendum's outcome: "People without German citizenship were not allowed to vote at the Hamburg referendum. However, about 15\% of all students in Hamburg's schools do not have German citizenship. Thus, an entire population group, whose children would be directly affected by the reform, was excluded from participating in the decision. These children would probably have benefited from the extension of elementary school the most."

${ }^{14}$ In this way, the referenda acted as a corrective to the electoral politics, in a logic similar to a recall procedure Geissel and Jung (2018) and Geißel and Jung (2020).
This article aimed to answer the question, how can claims be authorized beyond elections. We have selected three democratic innovations and traced claims through three stages of the claimmaking process: the making of a claim, authorization of claims, and acceptance of claims. Building on the typology developed by Guasti and Geissel (2019), we differentiated between acceptance 
TABLE 4 | Comparative overview of authorization in three democratic innovations.

\begin{tabular}{|c|c|c|c|}
\hline Case study & Frankfurt KAV & Münster PB & Hamburg referendum \\
\hline Type & Elected representative body of foreigners & Municipal participative budgeting & Citizens initiative initiated legislative referendum \\
\hline Timing & 2006-2017 & 2016 & 2008-2010 \\
\hline Number of claims & 284 & 20 & 70 \\
\hline Authorization authority & Municipal council & Municipal council & Eligible voters \\
\hline$\%$ Of accepted claims & $10 \%$ & $40 \%$ & $22 \%$ \\
\hline
\end{tabular}

Source: CLAIMS Frankfurt.

by the claimed constituency and authorization by the relevant decision-making authority. Each of the four types of claims requires different forms of authorization. Claims of representation, as well as claims of misrepresentation, can be authorized as well by the claimed constituency as by the respective authorities. Claims of interest/values can be authorized by the authorities but only indirectly by an unclear constituency, which is not claimed explicitly. Proclamations can only be authorized by the authorities (see Table 3).

Considering authorization mechanisms by constituencies, in all three cases, voting was a form of authorization by the constituency - election (KAV), referendum (Hamburg), online voting (Münster). Authorization by the respective (claimed) constituency turned out to be more complicated than expected. We found a significant discrepancy between the claimed constituency, the actually affected audience, and the formally intended (legally enfranchised) constituency. In some cases, the gap between the affected audience and the legally enfranchised constituency was relatively wide (Hamburg); in other cases, the process itself was inclusive - i.e., those affected were enfranchised to participate in the process. However, even when those affected were enfranchised, only a small portion participated (KAV, Münster). Finally, in one case (KAV), the claim-making process served to construct a different constituency than the legally prescribed constituency (KAV).

The decision-making authority included the municipal government (KAV, Münster) and the voters (Hamburg). Decision-making authorities employed different criteria for the authorization of claims. For the Frankfurt government, the critical criteria were the overlap between claimed and intended constituency. For Münster, government effectiveness and feasibility of claims represented the main criteria. In Hamburg, the voters decided, and their affected interest were the main criteria.

Claim-making in democratic innovations is fractured and incomplete. Nevertheless, this is not the reason to dismiss democratic innovations as possible loci of representation; on the contrary, seen thorugh the prism of claim-making, all representation - electoral and nonelectoral - is partial. Focusing on the authorization of claims in democratic innovations provides novel inference about the potential and limits of democratic innovations for broadening democratic representation (cf. Plotke, 1997).

Our cases resonate with Urbinati's agonistic conception of representation as advocacy (Urbinati, 2000). Especially the cases of Frankfurt and Hamburg show that clashes within claim-making do not only include competing interests, but also who is represented within these democratic innovations. Furthermore, we also show the importance of voice for historically marginalized groups (non-citizens, children; cf. Williams, 2000); while the constituency might accept a claim-maker as its representative, the relevant authority might reject the claim-maker, his claim, or both - if the interests of the group clash with formal (legal) boundaries or rules (cf. Rehfeld, 2006). We confirm the importance of the context under which claim-making occurs (cf. Saward, 2006; Saward, 2010). These contexts (the design of democratic innovations) determine the types of claims, their acceptance, and authorization.

Our approach fills several gaps in the existing literature on authorization (Kuyper, 2016; Heinisch and Werner, 2019; Joschko and Glaser, 2019). Kuyper's approach assesses the process as a whole, while the approach outlined here enables scholars to focus on individual claims - providing inference on the performative elements of representation beyond elections. For Heinisch and Werner (2019) elections and descriptive overlap between elected representatives and claimed constituency remain core authorization mechanisms. Our approach enables scholars to study the authorization of claims beyond elections, bridging both the traditional and constructivist representation. Finally, the sophisticated data used by Joschko and Glaser (2019) to identify constituencies and asses validation, is not available for most claims made outside the parliamentary arena. Thus, our approach offers broader applicability, especially to the scholars of nonelectoral representation.

The contribution of this paper is three-fold. To the scholars of traditional representation, we want to demonstrate that representation exists beyond traditional parliamentary politics and can be systematically analyzed. To the scholars of constructivist representation, we offer a way to assess authorization systematically. Moreover, for scholars of democratic innovations, this is an invitation to use claimmaking to better understand the dynamics within democratic innovations.

Our study has important limitations. The process of tracing claims is labor-intensive and time-consuming, relies on data availability, requires in-depth qualitative research, and comparability across different types of democratic innovations is only achieved at a higher level of abstraction. 
There is a broad scope of authorization mechanisms, and authenticity or descriptive representation are only two of its many underlying logics (cf. Kuyper, 2016; Heinisch and Werner, 2019). Our study shows that distinguishing between authorization by the constituency and the decision-making authority enables us to understand the dynamics of representation better. Therefore, we propose future research to go beyond elections as the only authorization mechanism and focus on other ways claims can be authorized/accepted (Guasti and Geissel, 2019; cf. Joschko and Glaser, 2019).

\section{DATA AVAILABILITY STATEMENT}

The raw data supporting the conclusions of this article will be made available by the authors, without undue reservation.

\section{REFERENCES}

Andeweg, R. B. (2003). Beyond representativeness? Trends in political representation. Eur. Rev. 11, 147-152. doi:10.1017/S1062798703000164

Ankersmit, F. R. (2002). Political representation. Palo Alto, CA: Stanford University Press.

Biezen, I. V. (2014). The end of party democracy as we know it? A tribute to Peter Mair. Irish Polit. Stud. 29 (2), 177-193. doi:10.1080/07907184.2014.897944

Bourdieu, P. (1991). Language and symbolic power. London, UK: Harvard University Press.

Dalton, R. J., Farrell, D. M., and Ian McAllister, I. (2011). Political parties and democratic linkage: how parties organize democracy. London, UK: Oxford University Press.

de Wilde, P. (2013). Representative claims analysis: theory meets method. J. Eur. Public Pol. 20 (2), 278-294. doi:10.1080/13501763.2013.746128

de Wilde, P. (2020). The quality of representative claims: uncovering a weakness in the defense of the liberal world order. Polit. Stud. 68 (2), 271-292. doi:10.1177/ 0032321719845199

Disch, L., Van de Sande, M., and Urbinati, N. (2019). The constructivist turn in political representation. Edinburgh, UK: Edinburgh University Press.

Disch, L. (2009). The people as "presupposition" of representative democracy-An essay on the political theory of Pierre Rosanvallon. Redescriptions: Yearb. Polit. Thought, Conceptual Hist. Feminist Theor. 12, 47-71. doi:10.7227/R.12.1.4

Disch, L. (2011). Toward a mobilization conception of democratic representation. Am. Polit. Sci. Rev. 105 (1) 100-114. doi:10.4324/9781315681696-6

Disch, L. (2015). The "Constructivist Turn" in democratic representation: a normative dead-end?. Constellations 22 (4), 487-499. doi:10.1111/1467-8675.12201

Dovi, S. (2017). Representation in context: constructing victims' claims in the international criminal court. Representation 53 3-4. doi:10.1080/00344893. 2018.1434231

Dryzek, J. S., and Simon, N. (2008). Discursive representation. Am. Political Sci. Rev. 102 481-493. doi:10.1017/S0003055408080325

Geißel, B., and Joas, M. (2013). Participatory democratic innovations in Europe: improving the quality of democracy? Leverkusen, NW: Verlag Barbara Budrich.

Geißel, B., and Jung, S. (2020). "Explaining institutional change towards recall in Germany," in The politics of recall elections, (London, UK: Palgrave Macmillan), 117-141.

Geissel, B., and Jung, S. (2018). Recall in Germany: explaining the use of a local democratic innovation. Democratization 25 (8), 1358-1378. doi:10.1080/ 13510347.2017.1398735

Guasti, P., and Geissel, B. (2019). Saward's concept of the representative claim revisited: an empirical perspective. Polit. Governance 7 (3), 98-111. doi:10. 17645/pag.v7i3.2103

Guasti, P., and Rezende de Almeida, D. (2019). Claims of misrepresentation: a comparison of Germany and Brazil. Polit. Governance 7 (3), 152-164. doi:10. 17645/pag.v7i3.2143

\section{AUTHOR CONTRIBUTIONS}

Iterative process - both co-authors worked on all parts of the article and contributed equally to the development of the typology of claims on representation. Additionally, $\mathrm{PG}$ was responsible for data collection an analysis (90\%) and the conclusions (70\%).

\section{FUNDING}

We thank the DFG and ANR for their kind funding of the research project "(New) Political Representative Claims: A Global View (France, Germany, Brazil, India, China)". We also thank the two reviewers, the editor, and participants of the panel 'Local Democratic Innovations and Local Representative Democracy', at the 2020 ECPR Virtual General Conference August 24-28, 2020.

Heinisch, R., and Werner, A. (2019). Who do populist radical right parties stand for? Representative claims, claim acceptance and descriptive representation in the Austrian FPÖ and German Alternative for Deutschland.Representation 4, 475-492. doi:10.1080/00344893.2019.1635196

Hirst, P. (2013). Associative democracy: New forms of economic and social governance. John Wiley and Sons.

Joschko, V., and Glaser, L. (2019). A new approach to map and quantify representative claims and measure their validation: a case study analysis. Polit. Governance 7 (3), 137-151. doi:10.17645/pag.v7i3.2150

Kitschelt, H. (2000). Linkages between citizens and politicians in democratic polities. Comp. Polit. Stud. 33 (6-7), 845-879. doi:10.1177/001041400003300607

Kroeber, C. (2018). How to measure the substantive representation of traditionally excluded groups in comparative research: a literature review and new data. Representation 3, 241-259. doi:10.1080/00344893.2018.1504112

Kuyper, J. W. (2016). Systemic representation: democracy, deliberation, and nonelectoral representatives. Am. Polit. Sci. Rev. 110 (2), 308. doi:10.1017/ S0003055416000095

Mair, P. (2008). The challenge to party government. West Eur. Polit. 31 (1-2), 211-234. doi:10.1080/01402380701835033

Mair, P. (2009). Representative versus responsible government." MPIfG Working Paper 09/8.

Manin, B. (1997). The principles of representative government. London, UK: Cambridge University Press.

Mansbridge, J. (1999). Should blacks represent blacks and women represent women? A contingent" yes. J. Polit. 61 (3), 628-657. doi:10.2307/2647821

Mansbridge, J. (2003). Rethinking representation. Am. Political Sci. Rev. 97 (4), 515-528.

Mansbridge, J. (2009). A "selection model" of political representation. J. Polit. Philos. 17 (4), 369-398. doi:10.1111/j.1467-9760.2009.00337.x

Mansbridge, J. (2011). Clarifying the concept of representation. Am. Polit. Sci. Rev., 621-630. doi:10.1017/S0003055411000189

Mansbridge, J. (2013). "Common Good". In The international encyclopedia of ethics. Editor LaFollette, H., Vol. II. Malden, MA: Wiley-Blackwell.

Mansbridge, J. (2015). Should workers represent workers?. Swiss Polit. Sci. Rev. 21 (2), 261-270. doi:10.1111/spsr.12160

Montanaro, L. (2012). The democratic legitimacy of self-appointed representatives. J. Polit. 74 (4), 1094-1107. doi:10.1017/S0022381612000515

Montanaro, L. (2017). "Who elected oxfam?," in A democratic defense of selfappointed representatives. (Cambridge, UK: Cambridge University Press).

Montanaro, L. (2018). "Who counts as a democratic representative?," in Creating political presence: The new politics of democratic representation. Editors D. Castiglione and J. Pollak. University of Chicago Press, 186

Näsström, S. (2006). Representative democracy as tautology: Ankersmit and lefort on representation. Eur. J. Polit. Theor. 5 (3), 321-342. doi:10.1177/ 2F1474885106064664

Phillips, A. (1995). The politics of presence. England, UK: Clarendon Press. 
Pitkin, H. F. (1967). The concept of representation. Berkeley, CA:University of California Press.

Pitkin, H. F. (2004). Representation and democracy: uneasy alliance. Scand. Polit. Stud. 27 (3), 335-342. doi:10.1111/j.1467-9477.2004.00109.x

Plotke, D. (1997). Representation is democracy. Constellations 4 (1), 19-34. doi:10. 1111/1467-8675.00033

Przeworski, A., Stokes, S. C., and Manin, B. (1999). Democracy, accountability, and representation. London, UK: Cambridge University Press.

Rehfeld, A. (2006). Towards a general theory of political representation. J. Polit. 68 (1), 1-21. doi:10.1111/j.1468-2508.2006.00365.x

Rosanvallon, P. (2008). Counter-democracy: politics in an age of distrust. London, UK: Cambridge University Press.

Runciman, David. (2007). The paradox of political representation. J. Polit. Philos. 15 (1), 93-114. doi:10.1111/j.1467-9760.2007.00266.x

Sartori, G. (1987). The theory of democracy revisited. London, UK: Chatham House Publications.

Saward, M. (2006). The representative claim. Contemp. Polit. Theor. 5 (3), 297-318. doi:10.1057/palgrave.cpt.9300234

Saward, M. (2008). Representation and democracy: revisions and possibilities. Sociol. Compass 2 (3), 1000-1013. doi:10.1111/j.1751-9020.2008.00102.x

Saward, M. (2009). Authorisation and authenticity: representation and the unelected. J. Polit. Philos. 17 (1), 1-22. doi:10.1111/j.1467-9760.2008. 00309.x

Saward, M. (2010). The representative claim. Oxford, UK: Oxford University Press.

Severs, E. (2012). Substantive representation through a claims-making lens: a strategy for the identification and analysis of substantive claims. Representation 48 (2), 169-181. doi:10.1080/00344893.2012.683491

Urbinati, N (2002). Mill on democracy: from the Athenian polis to representative government. University of Chicago Press.
Urbinati, N., and Warren, M. E. (2008). The concept of representation in contemporary democratic theory. Annu. Rev. Polit. Sci. 11, 387-412. doi:10. 1146/annurev.polisci.11.053006.190533

Urbinati, N. (2000). Representation as advocacy: a study of democratic deliberation. Polit. Theor. 28 (6), 758-786. doi:10.1177/0090591700028006003

Van Biezen, I., and Saward, M. (2008). Democratic theorists and party scholars: why they don't talk to each other, and why they should. Perspect. Polit. 6 (1), 21-35. doi:10.1017/S1537592708080043

Warren, M. E., and Hilary, P. (2008). Designing deliberative democracy: The British Columbia citizens' assembly. Cambridge, UK: Cambridge University Press, 1-19.

Warren, M. E. (2001). Democracy and association. Princeton, NJ: Princeton University Press.

Williams, M. S. (2000). Voice, trust, and memory: marginalized groups and the failings of liberal representation. Princeton, NJ: Princeton University Press.

Zulianello, M., and Ceccobelli, D. (2020). Don't call it climate populism: on Greta thunberg's technocratic ecocentrism. The political quarterly. 91 (3), 623-631. doi:10.1111/1467-923X.12858

Conflict of Interest: The authors declare that the research was conducted in the absence of any commercial or financial relationships that could be construed as a potential conflict of interest.

Copyright $(2021$ Guasti and Geissel. This is an open-access article distributed under the terms of the Creative Commons Attribution License (CC BY). The use, distribution or reproduction in other forums is permitted, provided the original author(s) and the copyright owner(s) are credited and that the original publication in this journal is cited, in accordance with accepted academic practice. No use, distribution or reproduction is permitted which does not comply with these terms. 